\title{
BMJ Association between cancer and contact Open allergy: a linkage study
}

\author{
Kaare Engkilde, Jacob P Thyssen, Torkil Menné, Jeanne D Johansen
}

To cite: Engkilde $\mathrm{K}$, Thyssen JP, Menné T, et al. Association between cancer and contact allergy: a linkage study. BMJ Open 2011;1: e000084. doi:10.1136/ bmjopen-2011-000084

- Prepublication history for this paper is available online. To view these files please visit the journal online (http:// bmjopen.bmj.com).

Received 1 February 2011 Accepted 8 April 2011

This final article is available for use under the terms of the Creative Commons Attribution Non-Commercial 2.0 Licence; see http://bmjopen.bmj.com

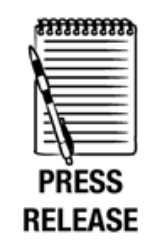

National Allergy Research Centre, Department of Dermato-Allergology, Copenhagen University Hospital Gentofte, University of Copenhagen, Hellerup, Denmark

Correspondence to Kaare Engkilde;

kaaeng02@geh.regionh.dk

\section{ABSTRACT}

Background: Contact allergy is a prevalent disorder. It is estimated that about $20 \%$ of the general population are allergic to one or more of the chemicals that constitute the European baseline patch test panel. While many studies have investigated associations between type I allergic disorders and cancer, few have looked into the association between cancer and contact allergy, a type IV allergy. By linking two clinical databases, the authors investigate the possible association between contact allergy and cancer. Methods: Record linkage of two different registers was performed: (1) a tertiary hospital register of dermatitis patients patch tested for contact allergy and (2) a nationwide cancer register (the Danish Cancer Register). After linking the two registers, only cancer subtypes with 40 or more patients registered were included in the analysis. The final associations were evaluated by logistic regression analysis.

Results: An inverse association between contact allergy and non-melanoma skin- and breast cancer, respectively, was identified in both sexes, and an inverse trend for brain cancer was found in women with contact allergy. Additionally, a positive association between contact allergy and bladder cancer was found.

Conclusion: The inverse associations support the immunosurveillance hypothesis (ie, individuals with an allergy are less likely to get cancer due to a triggered immune system), while the positive association with bladder cancer could be due to accumulations of chemical metabolites in the bladder. The authors' findings add to the limited knowledge about contact allergy and the risk of cancer.

\section{INTRODUCTION}

About $20 \%$ of Danish adults are contactallergic to chemicals and metals common in the environment. ${ }^{12}$ Contact allergy is caused by skin contact with low-molecular-weight non-protein chemicals, referred to as haptens, and can progress to allergic contact dermatitis if re-exposure exceeds the individual's threshold. ${ }^{3}$ Allergic contact dermatitis is a cutaneous delayed-type hypersensitivity reaction mediated by haptenspecific $\mathrm{T}$ cells. ${ }^{4}$ A possible association between type 1 allergic hypersensitivity reac-

\section{ARTICLE SUMMARY}

\section{Article focus}

- Cancer and allergy have previously been shown to be associated. The associations are mostly inverse, adding weight to the theory that enhanced tumour immunosurveillance is present in allergic individuals.

- The epidemiological studies showing these findings were predominantly on type I allergy; the present study investigated the association between type IV allergy and cancer.

\section{Key messages}

- An association seemingly exists between contact allergy and cancer. In light of previous findings of an association between bladder cancer and hair-dye use, the association between bladder cancer and contact allergy we found is interesting.

Strengths and limitations of this study

- This is a novel study investigating cancer and its possible association with a type IV allergy. The analysis was possible due to large, validated patient registers.

- As this is not a prospective cohort study, it lacks the ability to prove causation.

tions, as observed in atopic diseases, and the unrestrained cell growth in cancer has long intrigued researchers. Some studies have reported both positive and inverse associations for allergic disorders; others have not found any significant associations, as reviewed in Sherman et al. ${ }^{5}$ Most recent epidemiological studies point towards atopic diseases being associated with a reduced risk of cancer. ${ }^{6}$ However, a major problem affecting many epidemiological studies on associations between atopy and cancer is the different way in which the studies define atopy. Additionally, some studies have included patients with allergic contact dermatitis, which is problematic, as the immune response differs greatly. ${ }^{6}$ To date, few studies have investigated the relationship between contact allergy and cancer. Contact allergy to metal dental restorations was found to be a potential risk factor for intraoral 
squamous cell carcinoma, ${ }^{7}$ and glioma appeared inversely associated with self-reported contact dermatitis. ${ }^{8}$ Thus, it remains unclear whether two prevalent disorders, cancer and contact allergy, are truly associated, and if so, in what direction. We have previously shown that contact allergy is inversely associated with autoimmune diseases such as type 1 diabetes and inflammatory bowel disease. ${ }^{9-11}$ This is a descriptive exploratory investigation of the possible association between contact allergy and cancer by using crosslinkage between our contact allergy database and the national cancer database (the Danish Cancer Registry).

\section{MATERIALS AND METHODS}

\section{Study population and allergy testing}

From November 1984 to December 2008, patch tests for contact allergy using the European baseline series were performed on 16922 (6113 men and 10809 women) patients with dermatitis at the Department of Dermatology, Gentofte Hospital, Denmark. The outcome of patch testing, sex and date of birth were recorded in the allergy database. The European baseline series contains the most prevalent contact allergens in the environment for the European continent. Patch testing was performed on the upper back using Trolab allergens (Hermal, Reinbek, Germany) and Finn Chambers (8 mm Epitest, Oy, Finland) on Scanpor tape (Norgesplaster A/S, Alpharma, Vennesla, Norway) for occlusion. Occlusion time was $48 \mathrm{~h}$, and the patches were read on Day 2, on Day 3 or 4, and on Day 5 or 7 according to international criteria from the International Contact Dermatitis Research Group (ICDRG). ${ }^{12} 13$ A positive allergic reaction was defined as at least homogeneous erythema and infiltration in the test area. The database contains information on the patch-test reading result for each day, but in the present study, a binary variable was constructed. Thus, a positive patchtest reaction on any reading day to any allergen in the European baseline series was considered positive. The study population has been detailed previously. ${ }^{14}$

\section{Linkage study}

At birth, or on immigration, all those with residency in Denmark receive a unique and personal identifier number, a CPR number, which can be used for identification in databases. This enables linkage of individual data between databases.

We used the unique identifier number to link the contact allergy database from Gentofte Hospital, a tertiary referral centre, with the Danish Cancer Registry, which contains codes of cancer diagnosis from the International Classification of Diseases, 7th or 10th revision (ICD7 and ICD10). The Danish Cancer Registry is a population-based registry containing nationwide data on cancer cases since 1943. The history of the Danish Cancer Registry was reviewed by Storm et al in $1997{ }^{15}$ Cancer types were defined according to the Nordic Cancer Registries (NORDCAN Database, http:// www.ancr.nu/nordcan.asp). The cancer types 'other leukaemia' and acute 'leukaemia' in the NORDCAN database were omitted from data analyses, as we considered the grouping 'leukaemia' to cover immunological aspects of this cancer type and be representative. Table 1 shows cancer types used from the NORDCAN database. Only cancer types for which we found 40 or more patients after the linkage were included in the logistic regression analyses. Age was calculated as the age at first positive patch-test outcome. When there was no positive patch-test reading, the age at first patchtest procedure was used. Based on the number of patients in different age groups, patients were stratified into five groups: $0-29$ years, $30-41$ years, $42-52$ years, $53-65$ years and $65<$ years.

The combined data file was analysed using logistic regression analysis with the patch-test outcome (contact allergy: 'yes' vs 'no') as the dependent variable and different cancer types as the independent variables, and controlled for sex and age. Lastly, we inserted interaction terms between sex and each cancer subtype (eg, sex $\times$ colon cancer, sex $\times$ lung cancer, etc) in the regression analysis to test whether we should stratify the analyses by sex. ORs with 95\% CIs were estimated using logistic regression. All data analyses were carried out using SPSS version 18.

\section{RESULTS}

Among 16922 patients patch-tested in the selected period, $6065(35.8 \%)$ had a positive reaction to at least one allergen on at least one occasion. The prevalence of contact allergy, however, differed between the sexes, as the prevalence was $26.1 \%$ in male patients and $41.4 \%$ in female patients.

After linkage with the Danish Cancer Registry, 3200 $(18.9 \%)$ dermatitis patients were identified with a benign tumour and/or a malignant cancer diagnosis, and $1207(37.7 \%)$ of these also had a positive patch test reaction. The distribution within different cancer groups (with $\geq 40$ cases) is shown in table 1 . Crude data analysis revealed a positive and significant association between being contact allergic and being registered in the cancer registry (Mantel-Haenszel common $\mathrm{OR}=1.1$; $\mathrm{p}$ value $=0.014,95 \%$ CI 1.02 to 1.20 ). Using logistic regression analyses with contact allergy as the dependent variable, we calculated ORs for different cancer groups and adjusted the analysis for sex and age. Breast cancer and non-melanoma skin cancer in both sexes were found to be inversely and significantly associated with contact allergy; for women, there was a trend for an inverse association between contact allergy and brain cancer. Bladder cancer was found to be positively and significantly associated with contact allergy. The sexspecific association for brain cancer was identified by investigating different interaction terms between cancer subtypes and sex. However, we found a significant interaction term only for brain/CNS cancer. Thus, when a subsequent adjusted regression analysis was performed 
Table 1 Sex-specific distribution of cancer types and contact allergy

\begin{tabular}{|c|c|c|c|c|c|c|c|}
\hline \multirow[b]{3}{*}{$\begin{array}{l}\text { Cancer groups } \\
\text { (NORDCAN) }\end{array}$} & \multicolumn{6}{|l|}{ Sex } & \multirow[b]{3}{*}{ Total } \\
\hline & \multicolumn{3}{|l|}{ Men } & \multicolumn{3}{|l|}{ Women } & \\
\hline & $\begin{array}{l}\text { No contact } \\
\text { allergy }\end{array}$ & $\begin{array}{l}\text { Contact } \\
\text { allergy }\end{array}$ & Total & $\begin{array}{l}\text { No contact } \\
\text { allergy }\end{array}$ & $\begin{array}{l}\text { Contact } \\
\text { allergy }\end{array}$ & Total & \\
\hline \multirow[t]{2}{*}{ Pancreas } & 11 & 4 & 15 & 13 & 17 & 30 & 45 \\
\hline & $24.4 \%$ & $8.9 \%$ & $33.3 \%$ & $28.9 \%$ & $37.8 \%$ & $66.7 \%$ & $100 \%$ \\
\hline \multirow[t]{2}{*}{ Brain/CNS } & 15 & 7 & 22 & 30 & 11 & 41 & 63 \\
\hline & $23.8 \%$ & $11.1 \%$ & $34.9 \%$ & $47.6 \%$ & $17.5 \%$ & $65.1 \%$ & $100 \%$ \\
\hline \multirow[t]{2}{*}{ Cervix uteri } & NA & NA & NA & 34 & 30 & 64 & 64 \\
\hline & & & & $53.1 \%$ & $46.9 \%$ & $100 \%$ & $100 \%$ \\
\hline \multirow[t]{2}{*}{ Leukaemia } & 27 & 7 & 34 & 24 & 13 & 37 & 71 \\
\hline & $38.0 \%$ & $9.9 \%$ & $47.9 \%$ & $33.8 \%$ & $18.3 \%$ & $52.1 \%$ & $100 \%$ \\
\hline \multirow[t]{2}{*}{ Lip, oral cavity and pharynx } & 30 & 15 & 45 & 16 & 12 & 28 & 73 \\
\hline & $41.1 \%$ & $20.5 \%$ & $61.6 \%$ & $21.9 \%$ & $16.4 \%$ & $38.4 \%$ & $100 \%$ \\
\hline \multirow[t]{2}{*}{ Corpus uteri } & NA & NA & NA & 48 & 38 & 86 & 86 \\
\hline & & & & $55.8 \%$ & $44.2 \%$ & $100 \%$ & $100 \%$ \\
\hline \multirow[t]{2}{*}{ Rectum and anus } & 41 & 14 & 55 & 29 & 17 & 46 & 101 \\
\hline & $40.6 \%$ & 13.9 & $54.5 \%$ & $28.7 \%$ & $16.8 \%$ & $45.5 \%$ & $100 \%$ \\
\hline \multirow[t]{2}{*}{ Melanoma of skin } & 32 & 11 & 43 & 40 & 21 & 61 & 104 \\
\hline & $30.8 \%$ & $10.6 \%$ & $41.3 \%$ & $38.5 \%$ & $20.2 \%$ & $58.7 \%$ & $100 \%$ \\
\hline \multirow[t]{2}{*}{ Prostate } & 86 & 36 & 122 & NA & NA & NA & 122 \\
\hline & $70.5 \%$ & $29.5 \%$ & $100 \%$ & & & & $100 \%$ \\
\hline \multirow[t]{2}{*}{ Colon } & 43 & 9 & 52 & 43 & 29 & 72 & 124 \\
\hline & $34.7 \%$ & $7.3 \%$ & $41.9 \%$ & $34.7 \%$ & $23.4 \%$ & $58.1 \%$ & $100 \%$ \\
\hline \multirow[t]{2}{*}{ Bladder, etc } & 63 & 33 & 96 & 21 & 22 & 43 & 139 \\
\hline & $45.3 \%$ & $23.7 \%$ & $69.1 \%$ & $15.1 \%$ & $15.8 \%$ & $30.9 \%$ & $100 \%$ \\
\hline \multirow[t]{2}{*}{ Lung } & 83 & 26 & 109 & 41 & 42 & 83 & 192 \\
\hline & $43.2 \%$ & $13.5 \%$ & $56.8 \%$ & $21.4 \%$ & $21.9 \%$ & $43.2 \%$ & $100 \%$ \\
\hline \multirow[t]{2}{*}{ Colorectal } & 83 & 23 & 106 & 71 & 46 & 117 & 223 \\
\hline & $37.2 \%$ & $10.3 \%$ & $47.5 \%$ & $31.8 \%$ & $20.6 \%$ & $52.5 \%$ & $100 \%$ \\
\hline \multirow[t]{2}{*}{ Breast } & 0 & 0 & 0 & 248 & 151 & 399 & 399 \\
\hline & & & & $62.2 \%$ & $37.8 \%$ & $100 \%$ & $100 \%$ \\
\hline \multirow[t]{2}{*}{ Skin, non-melanoma } & 203 & 72 & 275 & 284 & 166 & 450 & 725 \\
\hline & $28.0 \%$ & $9.9 \%$ & $37.9 \%$ & $39.2 \%$ & $22.9 \%$ & $62.1 \%$ & $100 \%$ \\
\hline \multirow{2}{*}{$\begin{array}{l}\text { All sites but non-melanoma } \\
\text { skin cancer }\end{array}$} & 531 & 209 & 740 & 663 & 452 & 1115 & 1855 \\
\hline & $28.6 \%$ & $11.3 \%$ & $39.9 \%$ & $35.7 \%$ & $24.4 \%$ & $60.1 \%$ & $100 \%$ \\
\hline \multirow[t]{2}{*}{ Total (allergy database) } & 4519 & 1594 & 6113 & 4471 & 6338 & 10809 & 16922 \\
\hline & $26.7 \%$ & $9.4 \%$ & $36.1 \%$ & $26.4 \%$ & $37.5 \%$ & $63.9 \%$ & $100 \%$ \\
\hline
\end{tabular}

only in female dermatitis patients, a trend towards an inverse association was found between brain/CNS cancer and contact allergy $(p=0.080 ; O R=0.36 \quad(95 \%$ $\mathrm{CI}=0.12$ to 1.13$)$ ). Table 2 shows the ORs for each cancer type, adjusted for age and sex, and the final analysis outcome, which included bladder, breast, brain/ CNS and skin cancer (non-melanoma), as well as the brain/cancer $\times$ sex interaction.

\section{DISCUSSION}

We found a significant and inverse association between contact allergy and breast cancer and non-melanoma skin cancer, respectively, as well as a significant and positive association between contact allergy and bladder cancer. Additionally, brain/CNS cancer in women was inversely associated with contact allergy, albeit the $\mathrm{p}$ value was above 0.050 ( $p$ value $=0.08)$.
The allergen database used in the study comprises patients patch-tested at Gentofte hospital, and as such the patch tests have been scored uniformly over the years. The hospital lies in the capital region of Denmark, a region where there is limited industrial exposure from pesticide manufacturing, synthetic rubber processing, petrochemical refinery, etc, which gives no immediate confounding due to working conditions known to cause cancer.

We did not account for smoking in our study, although smoking may increase the risk of developing nickel contact allergy and some types of cancer. ${ }^{16} 17$ However, we found no association with lung or oral cancers, which are positively associated with smoking, ${ }^{18}$ but we did find a positive association with bladder cancer, which could have been partially caused by smoking, as smoking is a known risk factor for bladder cancer. ${ }^{19}$ Smoking can also be a risk factor for non-melanoma skin cancer, ${ }^{20} 21$ 
Table 2 Logistic analysis for the individual cancer group adjusted for age and sex

\begin{tabular}{|c|c|c|}
\hline $\begin{array}{l}\text { Cancer groups } \\
\text { (NORDCAN) }\end{array}$ & p Value & OR $(95 \% \mathrm{Cl})$ \\
\hline Pancreas & 0.184 & 1.50 (0.83 to 2.72$)$ \\
\hline Brain/CNS & 0.159 & 0.66 (0.38 to 1.16$)$ \\
\hline Cervix uteri & 0.503 & $1.18(0.73$ to 1.94$)$ \\
\hline Leukaemia & 0.233 & $0.73(0.43$ to 1.23$)$ \\
\hline Lip, oral cavity and pharynx & 0.496 & 1.18 (0.73 to 1.92$)$ \\
\hline Corpus uteri & 0.797 & 1.06 (0.69 to 1.62$)$ \\
\hline Rectum and anus & 0.470 & $0.85(0.55$ to 1.31$)$ \\
\hline Melanoma of skin & 0.262 & 0.79 (0.51 to 1.20$)$ \\
\hline Prostate & 0.455 & $1.16(0.78$ to 1.73$)$ \\
\hline Colon & 0.215 & $0.78(0.53$ to 1.15$)$ \\
\hline Bladder, etc & 0.039 & 1.44 (1.02 to 2.05$)$ \\
\hline Lung & 0.720 & 1.06 (0.78 to 1.43$)$ \\
\hline Colorectal & 0.187 & $0.82(0.61$ to 1.10$)$ \\
\hline Breast & 0.031 & 0.80 (0.65 to 0.98$)$ \\
\hline Skin, non-melanoma & 0.020 & 0.82 (0.70 to 0.97$)$ \\
\hline All sites but non-melanoma skin cancer & 0.415 & 0.96 (0.86 to 1.06$)$ \\
\hline \multicolumn{3}{|l|}{ Final logistic analysis } \\
\hline Bladder, etc & 0.040 & 1.44 (1.02 to 2.05$)$ \\
\hline Breast & 0.035 & 0.80 (0.65 to 0.98$)$ \\
\hline Skin, non-melanoma & 0.021 & 0.83 (0.70 to 0.97$)$ \\
\hline Brain/CNS & 0.513 & 1.35 (0.55 to 3.33$)$ \\
\hline Brain/CNS $\times$ sex & 0.080 & $0.36(0.12$ to 1.13$)$ \\
\hline
\end{tabular}

a modest risk factor for brain cancer, ${ }^{22} 23$ and is speculated to be a risk factor for breast cancer. ${ }^{24}$ However, as these cancer types were inversely associated with contact allergy, a bias caused by smoking would have weakened the association.

Although most patients with contact allergy have been treated intermittently with topical steroids, only a minority have been treated with systemic immunosuppressants. The latter treatment might be associated with non-melanoma skin cancer, as TNF- $\alpha$-inhibitors and prednisolone have been shown to increase the risk of non-melanoma skin cancer in rheumatoid-arthritis patients. ${ }^{25}$ Additionally, a study on squamous-cell carcinoma found a positive association in patients hospitalised for chronic diseases, including skin disease and among these allergic contact dermatitis. ${ }^{26}$ In our study, we found an inverse association between contact allergy and non-melanoma skin cancer, and treatment biases could therefore have weakened this inverse association.

Self-reported contact eczema has been found to be inversely correlated to glioma and meningioma. ${ }^{8}$ The self-reported contact eczema had the lowest OR of any of the allergic conditions for both glioma and meningioma, although the CI for meningioma was wide and close to 1 . Glioma patients have been shown to have impaired immunity, ${ }^{27}$ and it is unknown whether the suppression is evident before diagnosis of the tumour. It has been suggested that hair dyeing can increase the risk of glioma $^{28}$ 29; however, we found an inverse association, even though hair dyeing is a risk factor for development of p-phenylenediamine contact allergy, for example.
Hair dyeing may also be a risk factor for developing bladder cancer. ${ }^{30} 31$ In our study, we found a positive association between contact allergy and bladder cancer, which may be caused by p-phenylenediamine contact allergy. Hair dyeing does not appear to be related to breast cancer. $^{32}$

It would have been interesting if we had analysed possible associations between specific allergens and cancer types in the current dataset, but owing to a lack of power, this was not possible.

Various hypotheses have been put forward to explain the associations between allergy and cancer. The 'antigenic stimulation' hypothesis has been suggested to explain positive associations. In this hypothesis, it is speculated that the increased stimulation of cell growth in allergy and chronic inflammation increases the likelihood of mutation of dividing stem cells and malignant proliferation. $^{5}$ To explain inverse associations, the immunosurveillance hypothesis has been suggested, where the allergic symptoms are the side effect of hyperimmunity. Additionally, tumours may suppress the immune system systemically and in the microenvironment of the tumour, ${ }^{33}$ as seen in glioma patients, who have a lower count of $\mathrm{CD} 4+\mathrm{T}$ cells overall and an increased fraction of $\mathrm{CD} 4+\mathrm{FOXP} 3+\mathrm{T}$ cells in the remaining fraction. ${ }^{34}$

In conclusion, contact allergy was found to be associated with four different cancer subtypes. Most of the associations were inverse, which might support the immunosurveillance hypothesis. The reason for these relations is uncertain and not necessarily the result of causality. More 
refined analyses, adjusting for social class and smoking, for instance, and studies focusing on specific chemical exposures are required to further our understanding of the role of contact allergies in the development of cancer. However, if these relations are aetiological, there are implications for understanding how contact allergy can affect cancer development and vice versa.

Our findings add to the limited knowledge of the association between contact allergy and cancer.

Acknowledgements Financial support from Aage Bang's Foundation and the Capital Region's Research Foundation is gratefully acknowledged.

Funding This research received no specific grant from any funding agency in the public, commercial or not-for-profit sectors; however, we are grateful for general financial support from Aage Bang's Foundation and the Capital Region's Research Foundation.

Competing interests None.

Contributors KE, TM and JDU designed the study. KE and JPT analysed and interpreted the data. KE and JPT drafted the manuscript, and all authors revised it critically. All authors gave their final approval of the version to be published.

Provenance and peer review Not commissioned; externally peer reviewed.

Data sharing statement No additional data available.

\section{REFERENCES}

1. Nielsen $\mathrm{NH}$, Linneberg $\mathrm{A}$, Menne $\mathrm{T}$, et al. Allergic contact sensitization in an adult Danish population: two cross-sectional surveys eight years apart (the Copenhagen Allergy Study). Acta Derm Venereol 2001:81:31-4.

2. Thyssen JP, Linneberg A, Menne T, et al. Contact allergy to allergens of the TRUE-test (panels 1 and 2) has decreased modestly in the general population. Br J Dermatol 2009;161:1124-9.

3. Rustemeyer T, van Hoogstraten IMW, von Blomberg BM, et al. Mechanisms in Allergic Contact Dermatitis. In: Frosch PJ, Menné T, Lepoittevin JP, eds. Contact Dermatitis. 4th edn. Berlin: Springer, 2006:11-43.

4. Vocanson M, Hennino A, Chavagnac C, et al. Contribution of CD4(+) and CD8(+) T-cells in contact hypersensitivity and allergic contact dermatitis. Expert Rev Clin Immunol 2005;1:75-86.

5. Sherman PW, Holland E, Sherman JS. Allergies: their role in cancer prevention. Q Rev Biol 2008;83:339-62.

6. Wang $\mathrm{H}$, Diepgen $\mathrm{TL}$. Is atopy a protective or a risk factor for cancer? A review of epidemiological studies. Allergy 2005;60:1098-111.

7. Hougeir FG, Yiannias JA, Hinni ML, et al. Oral metal contact allergy: a pilot study on the cause of oral squamous cell carcinoma. Int $J$ Dermatol 2006;45:265-71.

8. Wigertz A, Lonn S, Schwartzbaum J, et al. Allergic conditions and brain tumor risk. Am J Epidemiol 2007;166:941-50.

9. Bangsgaard N, Engkilde K, Thyssen JP, et al. Inverse relationship between contact allergy and psoriasis: results from a patient- and a population-based study. Br J Dermatol 2009;161:1119-23.

10. Engkilde K, Menne T, Johansen JD. Inflammatory bowel disease in relation to contact allergy: a patient-based study. Scand $J$ Gastroenterol 2007;42:572-6.

11. Engkilde K, Menné T, Johansen JD. Inverse relationship between allergic contact dermatitis and type 1 diabetes mellitus: a retrospective clinic-based study. Diabetologia 2006;49:644-7.
12. Wilkinson DS, Fregert S, Magnusson B, et al. Terminology of contact dermatitis. Acta Derm Venereol 1970;50:287-92.

13. Wahlberg JE, Lindberg M. Patch Testing. In: Frosch PJ, Menné T, Lepoittevin J-P, eds. Contact Dermatitis. 4th edn. Berlin: Springer, 2006:365-90.

14. Carlsen BC, Menne T, Johansen JD. 20 Years of standard patch testing in an eczema population with focus on patients with multiple contact allergies. Contact Dermatitis 2007;57:76-83.

15. Storm HH, Michelsen EV, Clemmensen IH, et al. The Danish Cancer Registry-history, content, quality and use. Dan Med Bull 1997;44:535-9.

16. Linneberg $\mathrm{A}$, Nielsen $\mathrm{NH}$, Menne $\mathrm{T}$, et al. Smoking might be a risk factor for contact allergy. J Allergy Clin Immunol 2003;111:980-4.

17. Thyssen JP, Johansen JD, Menne T, et al. Effect of tobacco smoking and alcohol consumption on the prevalence of nickel sensitization and contact sensitization. Acta Derm Venereol 2010;90:27-33.

18. Gandini S, Botteri E, lodice $S$, et al. Tobacco smoking and cancer: a meta-analysis. Int $J$ Cancer 2008;122:155-64.

19. Baris D, Karagas MR, Verrill C, et al. A case-control study of smoking and bladder cancer risk: emergent patterns over time. J Natl Cancer Inst 2009;101:1553-61.

20. De Hertog SA, Wensveen CA, Bastiaens MT, et al. Relation between smoking and skin cancer. J Clin Oncol 2001;19:231-8.

21. Milan T, Verkasalo PK, Kaprio J, et al. Malignant skin cancers in the Finnish Twin Cohort: a population-based study, 1976-97. Br J Dermatol 2002:147:509-12.

22. Efird JT, Friedman GD, Sidney S, et al. The risk for malignant primary adult-onset glioma in a large, multiethnic, managed-care cohort: cigarette smoking and other lifestyle behaviors. J Neurooncol 2004;68:57-69.

23. Silvera SA, Miller AB, Rohan TE. Cigarette smoking and risk of glioma: a prospective cohort study. Int $J$ Cancer 2006;118:1848-51.

24. Cui $Y$, Miller AB, Rohan TE. Cigarette smoking and breast cancer risk: update of a prospective cohort study. Breast Cancer Res Treat 2006;100:293-9.

25. Chakravarty EF, Michaud K, Wolfe F. Skin cancer, rheumatoid arthritis, and tumor necrosis factor inhibitors. $J$ Rheumatol 2005;32:2130-5.

26. Jensen $A \varnothing$, Olesen $A B$, Dethlefsen $C$, et al. Chronic diseases requiring hospitalization and risk of non-melanoma skin cancers-a population based study from Denmark. J Invest Dermatol 2008;128:926-31.

27. Dix AR, Brooks WH, Roszman TL, et al. Immune defects observed in patients with primary malignant brain tumors. $J$ Neuroimmunol 1999;100:216-32.

28. Heineman EF, Ward MH, McComb RD, et al. Hair dyes and risk of glioma among Nebraska women. Cancer Causes Control 2005;16:857-64.

29. Bluhm EC, Zahm SH, Fine HA, et al. Personal hair dye use and risks of glioma, meningioma, and acoustic neuroma among adults. $A m \mathrm{~J}$ Epidemiol 2007;165:63-71.

30. Espinoza F, Silverman D, Kogevinas M, et al. Micronuclei assessment in the urothelial cells of women using hair dyes and its modulation by genetic polymorphisms. Cancer Lett 2008;263:259-66.

31. Gago-Dominguez M, Castelao JE, Yuan JM, et al. Use of permanent hair dyes and bladder-cancer risk. Int J Cancer 2001;91:575-9.

32. Zheng T, Holford TR, Mayne ST, et al. Use of hair colouring products and breast cancer risk: a case-control study in Connecticut. Eur $J$ Cancer 2002;38:1647-52.

33. Rabinovich GA, Gabrilovich D, Sotomayor EM. Immunosuppressive strategies that are mediated by tumor cells. Annu Rev Immunol 2007;25:267-96.

34. Fecci PE, Mitchell DA, Whitesides JF, et al. Increased regulatory T-cell fraction amidst a diminished CD4 compartment explains cellular immune defects in patients with malignant glioma. Cancer Res 2006:66:3294-302. 